\title{
Protein-protein interaction analysis to identify biomarker networks for endometriosis
}

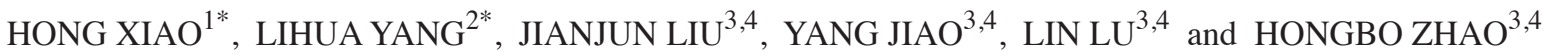 \\ ${ }^{1}$ Department of Anesthesiology, West China Hospital, Sichuan University, Chengdu, Sichuan 610041; \\ ${ }^{2}$ Department of Gynecology, The Second Affiliated Hospital of Kunming Medical University, \\ Kunming, Yunnan 650101; ${ }^{3}$ Institute of Molecular and Clinical Medicine, Kunming Medical University; \\ ${ }^{4}$ Yunnan Key Laboratory of Stem Cell and Regenerative Medicine, Kunming, Yunnan 650500, P.R. China
}

Received December 26, 2015; Accepted February 17, 2017

DOI: $10.3892 / \mathrm{etm} .2017 .5185$

\begin{abstract}
The identification of biomarkers and their interaction network involved in the processes of endometriosis is a critical step in understanding the underlying mechanisms of the disease. The aim of the present study was to construct biomarker networks of endometriosis that integrated human protein-protein interactions and known disease-causing genes. Endometriosis-associated genes were extracted from Genotator and DisGeNet and biomarker network and pathway analyses were constructed using atBioNet. Of 100 input genes, 96 were strongly mapped to six major modules. The majority of the pathways in the first module were associated with the proliferation of cancer cells, the enriched pathways in module B were associated with the immune system and infectious diseases, module $\mathrm{C}$ included pathways related to immune and metastasis, the enriched pathways in module $\mathrm{D}$ were associated with inflammatory processes, and the majority of the pathways in module $\mathrm{E}$ were related to replication and repair. The present approach identified known and potential biomarkers in endometriosis. The identified biomarker networks are highly enriched in biological pathways associated with endometriosis, which may provide further insight into the molecular mechanisms underlying endometriosis.
\end{abstract}

\section{Introduction}

Endometriosis is a benign gynecological disorder that occurs in $10 \%$ of women of reproductive age (1). The main symptoms

Correspondence to: Dr Hongbo Zhao, Institute of Molecular and Clinical Medicine, Kunming Medical University, 1168 West Chunrong Road, Yuhua Street, Kunming, Yunnan 650500, P.R. China

E-mail: zhaohongbo@kmmu.edu.cn

${ }^{*}$ Contributed equally

Key words: endometriosis, protein-protein interaction, biomarker, network, module include infertility and chronic pelvic pain (2). Although there are a number of studies on endometriosis, the majority of the mechanisms are not well understood (3-6). Identifying disease biomarkers and their interaction networks is important to improve the understanding of the causes of endometriosis, as well as to improve medical care.

Several databases have been developed that store associations between genes and diseases, such as the Online Mendelian Inheritance in Man (7), the Human Gene Mutation Database (8) and the Genetic Association Database (9). Due to the nature of the database curation process, the data are incomplete. Some gene-disease databases that combine gene-associated diseases from several expert, public and curated data sources also exist $(10,11)$. With the rapid accumulation of gene-disease data, increasing research has been utilizing the gene-disease database as a start-point to mine disease biomarkers (12-14).

Protein-protein interaction (PPI) networks include information on the biological processes and molecular functions of cells and have been widely used to characterize the underlying mechanisms of genes associated with complex diseases $(15,16)$. The majority of human diseases are caused by a group of correlated molecules or a network, rather than a single gene (17). Thus, identification and validation of biomarker networks is critical to disease diagnosis, prognosis and treatment.

In the present study, a disease network of endometriosis that integrated human PPIs and known disease-causing genes was constructed. Endometriosis-causing genes were identified from gene-disease databases. Subsequently, bioinformatics approaches, including PPI network construction, module analysis, functional enrichment analysis and text mining, were utilized in the research. The results of the present study may provide new targets for endometriosis therapy and identify the potential mechanisms of the disease.

\section{Materials and methods}

Seed gene selection. Endometriosis-related genes were obtained from Genotator (http://genotator.hms.harvard .edu/) (10) and DisGeNET (http://www.disgenet.org) (11). For each tool, gene lists were extracted using the query term, endometriosis. Genotator provides high quality gene-disease 
associations based upon data from 11 trustworthy resources. DisGeNET is a discovery platform that integrates information on gene-disease associations from several public data sources and literature (11). Thus, a list of genes that had been experimentally validated to be associated with endometriosis were obtained.

Disease-gene network construction. Endometriosis-associated genes were submitted to atBioNet (https://www.fda. gov/ScienceResearch/BioinformaticsTools/ucm285284.htm) and PPIs were obtained. atBioNet is a network analysis tool that provides a systematic insight into gene interactions by examining significant functional modules (18). The default option is 'Human Database' that combines data from a variety of public PPI sources, including BioGRID (19), the Database of Interacting Proteins (20), the Human Protein Reference Database (21), IntAct (22), the Molecular INTeraction database (23), REACTOME (24) and the Signaling Pathways Integrated Knowledge Engine (25). The protein interaction network included 12,043 human proteins and 132,605 interactions. SCAN algorithm was used to identify functional modules and perform assessment of generated gene networks for biomarker discovery (26).

Pathway enrichment analysis. To identify potential roles of genes in endometriosis, the Kyoto Encyclopedia of Genes and Genomes (KEGG) (27) pathway analysis component in atBioNet was used. Overrepresented KEGG pathways for each module were ranked according to the $\mathrm{P}$-value obtained from Fisher's exact tests.

Literature mining. To identify the genes associated with endometriosis, mining from the PubMed database (https://www. ncbi.nlm.nih.gov/pubmed) with keywords 'gene symbol' and 'endometriosis' was conducted. Subsequently, the articles associated with endometriosis were screened manually. A high number of papers indicated that the relationship between potential biomarker genes and endometriosis is well studied and documented.

\section{Results}

Screening of seed genes related to endometriosis. A total of 271 and 229 genes were extracted from Genotator and DisGeNET, respectively. The common genes, of which there were 100 , were used as seed genes to generate functional modules.

Construction of biomarker networks. Of 100 input genes, 96 were found in GenBank (https://www.ncbi.nlm.nih. gov/genbank/), and network clustering identified six major sub network modules from the original PPI network (Fig. 1). Hub genes in each module were identified (Table I).

KEGG pathway analysis. A total of 2,429 genes from the KEGG human database were added to the PPI network and genes in each module were selected for pathway enrichment analysis. The top 10 significantly enriched KEGG pathways for the six modules in endometriosis are demonstrated in Table II. Module A was a cancer cell proliferation module. The majority of the pathways in
Table I. Hub genes in each module.

\begin{tabular}{|c|c|c|}
\hline Module & Gene ID & Gene symbol \\
\hline A & 196 & AHR \\
\hline A & 367 & AR \\
\hline A & 405 & ARNT \\
\hline A & 2099 & ESR1 \\
\hline A & 8204 & NRIP1 \\
\hline A & 2100 & ESR2 \\
\hline A & 7157 & TP53 \\
\hline A & 2516 & NR5A1 \\
\hline A & 2908 & NR3C1 \\
\hline A & 5241 & PGR \\
\hline B & 3557 & IL1RN \\
\hline B & 3552 & IL1A \\
\hline B & 3554 & IL1R1 \\
\hline B & 3553 & IL1B \\
\hline B & 3560 & IL2RB \\
\hline B & 3600 & IL15 \\
\hline B & 3565 & IL4 \\
\hline B & 3586 & IL10 \\
\hline B & 3606 & IL18 \\
\hline $\mathrm{C}$ & 4316 & MMP7 \\
\hline $\mathrm{C}$ & 3479 & IGF1 \\
\hline $\mathrm{C}$ & 3484 & IGFBP1 \\
\hline $\mathrm{C}$ & 4312 & MMP1 \\
\hline $\mathrm{C}$ & 5069 & PAPPA \\
\hline $\mathrm{C}$ & 7077 & TIMP2 \\
\hline $\mathrm{C}$ & 4322 & MMP13 \\
\hline $\mathrm{C}$ & 4321 & MMP12 \\
\hline $\mathrm{D}$ & 3106 & HLA-B \\
\hline $\mathrm{D}$ & 3105 & HLA-A \\
\hline $\mathrm{D}$ & 3107 & HLA-C \\
\hline D & 3115 & HLA-DPB 1 \\
\hline $\mathrm{D}$ & 3117 & HLA-DQA1 \\
\hline D & 3119 & HLA-DQB1 \\
\hline D & 3123 & HLA-DRB1 \\
\hline $\mathrm{E}$ & 328 & APEX1 \\
\hline E & 4968 & OGG1 \\
\hline E & 7515 & $\mathrm{XRCC} 1$ \\
\hline E & 2068 & ERCC2 \\
\hline E & 2073 & ERCC5 \\
\hline F & 355 & FAS \\
\hline $\mathrm{F}$ & 356 & FASLG \\
\hline $\mathrm{F}$ & 7132 & TNFRSF1A \\
\hline $\mathrm{F}$ & 7124 & TNF \\
\hline $\mathrm{F}$ & 4049 & LTA \\
\hline
\end{tabular}

the first module were related to the proliferation of cancer cells and were associated with pathways in cancer, the cell cycle, oocyte meiosis, adherens junctions and the Wnt signaling pathway. The enriched pathways in module B were associated with the immune system and infectious diseases, including cytokine-cytokine 

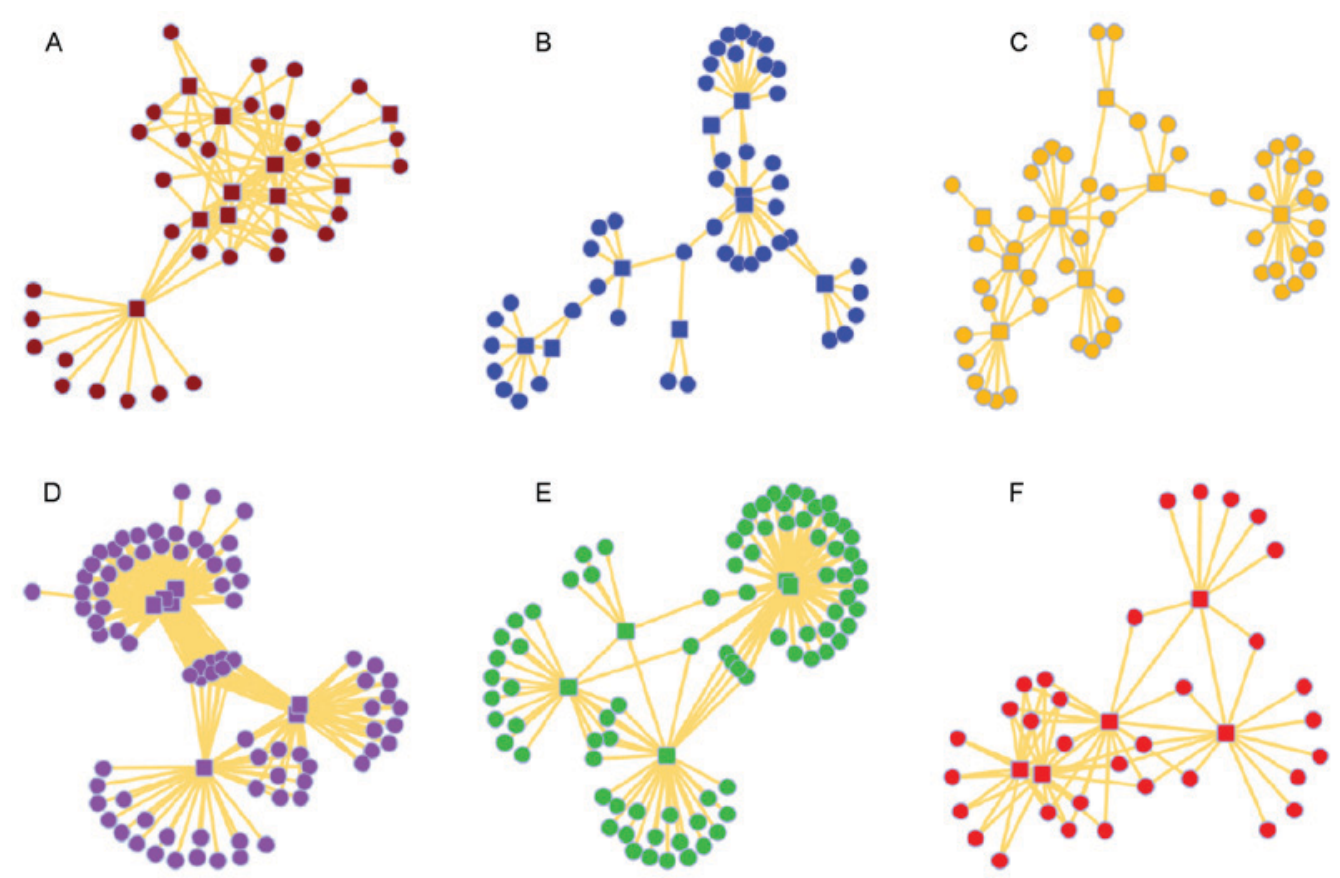

Figure 1. Network constructed from endometriosis-associated genes. Squares represent seed genes and circles represent added genes. (A-F) represent modules A-F, respectively.

receptor interaction, the mitogen-activated protein kinase signaling pathway, the Janus kinase-signal transducer and activator of transcription (JAK-STAT) signaling pathway, the intestinal immune network for immunoglobulin (Ig) A production and Toll-like receptor signaling pathways. Module $\mathrm{C}$ was associated with complement and coagulation cascades, extracellular matrix-receptor interaction, focal adhesion, and proteasome and hematopoietic cell lineages associated with immune and metastasis. The enriched pathways in module D were associated with inflammatory responses, including phagosome, cell adhesion molecules, antigen processing and presentation, natural killer cell mediated cytotoxicity, $\mathrm{T}$ cell receptor signaling pathways and the intestinal immune network for IgA production. The majority of the pathways in module $\mathrm{E}$ were related to processes of replication and repair, including DNA replication, base excision repair, nucleotide excision repair, mismatch repair and homologous recombination.

Endometriosis-associated genes identified in literature. A total of 15 genes, seven in the first module and eight in the second module, have previously been reported in literature to be candidate biomarkers for endometriosis (Fig. 2). For example, women with endometriosis had significantly higher SOX2 expression levels compared to controls (Fig. 2A) (28). Also, various genes identified in the second module (Fig. 2B), including CASP3, S100A13 and IL1R2, have been reported to be associated with endometriosis (29-31). Details for the 15 literature-confirmed potential endometriosis biomarkers are listed in Table III.

\section{Discussion}

The cause of endometriosis is not entirely understood. No single theory is able to explain all cases of endometriosis. The present study implemented PPI for endometriosis biomarker network analysis and identified biologically relevant functional modules. A number of genes and pathways identified in the modules have already been reported to participate in the pathogenesis of endometriosis (32-36).

Although endometriosis is a benign disorder, several common characteristics of this disease are shared with invasive cancer (37). Previous epidemiologic studies have demonstrated that women with endometriosis have an increased risk of ovarian and breast cancer $(38,39)$. Coincidentally, the three chromosomal regions (9p, 11q and 22q) that have demonstrated loss of heterozygosity in ovarian endometriosis were the same that were observed in ovarian tumors (40). These studies have demonstrated that the inactivation of tumor suppressor genes has an important role in the development of endometriosis. The results of the present study demonstrated that expression of cancer-related pathways are significantly imbalanced in endometriosis in module A. The hub genes identified were AHR, AR, ARNT, ESR1, NRIP1, ESR2, TP53, NR5A1, NR3C1 and PGR.

The enriched pathways in module B were associated with the immune system and infectious diseases. The presence of proinflammatory cytokines in the peritoneal fluid of patients with endometriosis has been reported in previous studies (41-43). Cytokines may regulate the actions of leukocytes in the peritoneal fluid or may act directly on the ectopic endometrium (44). Dysregulation of the JAK-STAT pathway is associated with various immune disorders (45), which was also demonstrated in the results of the present study. IL10RA, IL15, IL10 and JAK3 from the Toll-like receptor signaling pathway and CASP1, IL18, IL1B and TRAF6 from the NOD-like receptor signaling pathway, which are important for generating mature proinflammatory cytokines, were also identified in this module and are confirmed by previous studies $(35,46)$. Module B also 
Table II. Top 10 KEGG pathways ranked by P-value for the top six modules in endometriosis.

\begin{tabular}{|c|c|c|c|}
\hline $\begin{array}{l}\text { Functional modules } \\
\text { (no. of genes) }\end{array}$ & $\begin{array}{l}\text { Map title } \\
\text { in KEGG }\end{array}$ & $\begin{array}{l}\text { No. of genes mapped } \\
\text { in the pathway }\end{array}$ & P-value ${ }^{a}$ \\
\hline \multirow[t]{10}{*}{ Module A $(n=42)$} & Pathways in cancer (hsa05200) & 7 & $<0.0001$ \\
\hline & Thyroid cancer (hsa05216) & 3 & $<0.0001$ \\
\hline & Prostate cancer (hsa05215) & 4 & 0.0001 \\
\hline & Oocyte meiosis (hsa04114) & 4 & 0.0003 \\
\hline & Neurotrophin signaling pathway (hsa04722) & 4 & 0.0005 \\
\hline & Cell cycle (hsa04110) & 4 & 0.0005 \\
\hline & Basal transcription factors (hsa03022) & 3 & 0.0005 \\
\hline & Colorectal cancer (hsa05210) & 3 & 0.0008 \\
\hline & Wnt signaling pathway (hsa04310) & 4 & 0.0009 \\
\hline & Renal cell carcinoma (hsa05211) & 3 & 0.0011 \\
\hline \multirow[t]{10}{*}{ Module B (n=54) } & Cytokine-cytokine receptor interaction (hsa04060) & 19 & $<0.0001$ \\
\hline & Apoptosis (hsa04210) & 11 & $<0.0001$ \\
\hline & JAK-STAT signaling pathway (hsa04630) & 15 & $<0.0001$ \\
\hline & Pertussis (hsa05133) & 9 & $<0.0001$ \\
\hline & Measles (hsa05162) & 11 & $<0.0001$ \\
\hline & Tuberculosis (hsa05152) & 11 & $<0.0001$ \\
\hline & Toxoplasmosis (hsa05145) & 9 & $<0.0001$ \\
\hline & Leishmaniasis (hsa05140) & 7 & $<0.0001$ \\
\hline & Intestinal immune network for IgA production (hsa04672) & 6 & $<0.0001$ \\
\hline & Toll-like receptor signaling pathway (hsa04620) & 7 & $<0.0001$ \\
\hline \multirow[t]{10}{*}{ Module C $(n=60)$} & Complement and coagulation cascades (hsa04610) & 6 & $<0.0001$ \\
\hline & Hypertrophic cardiomyopathy (hsa05410) & 4 & 0.0009 \\
\hline & ECM-receptor interaction (hsa04512) & 4 & 0.0010 \\
\hline & Dilated cardiomyopathy (hsa05414) & 4 & 0.0012 \\
\hline & Hematopoietic cell lineage (hsa04640) & 3 & 0.0111 \\
\hline & Focal adhesion (hsa04510) & 4 & 0.0208 \\
\hline & Proteasome (hsa03050) & 2 & 0.0237 \\
\hline & Pathways in cancer (hsa05200) & 5 & 0.0280 \\
\hline & Vitamin B6 metabolism (hsa00750) & 1 & 0.0316 \\
\hline & Staphylococcus aureus infection (hsa05150) & 2 & 0.0355 \\
\hline \multirow[t]{10}{*}{ Module D (n=87) } & Phagosome (hsa04145) & 17 & $<0.0001$ \\
\hline & Cell adhesion molecules (hsa04514) & 24 & $<0.0001$ \\
\hline & Antigen processing and presentation (hsa04612) & 24 & $<0.0001$ \\
\hline & Natural killer cell mediated cytotoxicity (hsa04650) & 13 & $<0.0001$ \\
\hline & T cell receptor signaling pathway (hsa04660) & 18 & $<0.0001$ \\
\hline & Intestinal immune network for IgA production (hsa04672) & 13 & $<0.0001$ \\
\hline & Type I diabetes mellitus (hsa04940) & 17 & $<0.0001$ \\
\hline & Leishmaniasis (hsa05140) & 14 & $<0.0001$ \\
\hline & Toxoplasmosis (hsa05145) & 13 & $<0.0001$ \\
\hline & Staphylococcus aureus infection (hsa05150) & 13 & $<0.0001$ \\
\hline \multirow[t]{10}{*}{ Module E (n=87) } & Purine metabolism (hsa00230) & 19 & $<0.0001$ \\
\hline & Pyrimidine metabolism (hsa00240) & 19 & $<0.0001$ \\
\hline & RNA polymerase (hsa03020) & 12 & $<0.0001$ \\
\hline & DNA replication (hsa03030) & 17 & $<0.0001$ \\
\hline & Base excision repair (hsa03410) & 22 & $<0.0001$ \\
\hline & Nucleotide excision repair (hsa03420) & 31 & $<0.0001$ \\
\hline & Mismatch repair (hsa03430) & 14 & $<0.0001$ \\
\hline & Homologous recombination (hsa03440) & 7 & $<0.0001$ \\
\hline & Huntington's disease (hsa05016) & 13 & $<0.0001$ \\
\hline & Basal transcription factors (hsa03022) & 6 & $<0.0001$ \\
\hline
\end{tabular}


Table II. Continued.

\begin{tabular}{|c|c|c|c|}
\hline $\begin{array}{l}\text { Functional modules } \\
\text { (no. of genes) }\end{array}$ & $\begin{array}{l}\text { Map title } \\
\text { in KEGG }\end{array}$ & $\begin{array}{l}\text { No. of genes mapped } \\
\text { in the pathway }\end{array}$ & P-value ${ }^{a}$ \\
\hline \multirow[t]{10}{*}{ Module F ( $\mathrm{n}=38)$} & Cytokine-cytokine receptor interaction (hsa04060) & 12 & $<0.0001$ \\
\hline & Apoptosis (hsa04210) & 14 & $<0.0001$ \\
\hline & RIG-I-like receptor signaling pathway (hsa04622) & 7 & $<0.0001$ \\
\hline & Tuberculosis (hsa05152) & 8 & $<0.0001$ \\
\hline & Pathways in cancer (hsa05200) & 10 & $<0.0001$ \\
\hline & Natural killer cell mediated cytotoxicity (hsa04650) & 7 & $<0.0001$ \\
\hline & Chagas disease (American trypanosomiasis; hsa05142) & 6 & $<0.0001$ \\
\hline & Alzheimer's disease (hsa05010) & 7 & $<0.0001$ \\
\hline & Osteoclast differentiation (hsa04380) & 6 & $<0.0001$ \\
\hline & Type I diabetes mellitus (hsa04940) & 4 & $<0.0001$ \\
\hline
\end{tabular}

${ }^{a}$ According to Fisher's exact test. KEGG, Kyoto Encyclopedia of Genes and Genomes; JAK-STAT, Janus kinase-signal transducer and activator of transcription; IgA, immunoglobulin A; ECM, extracellular matrix.

A

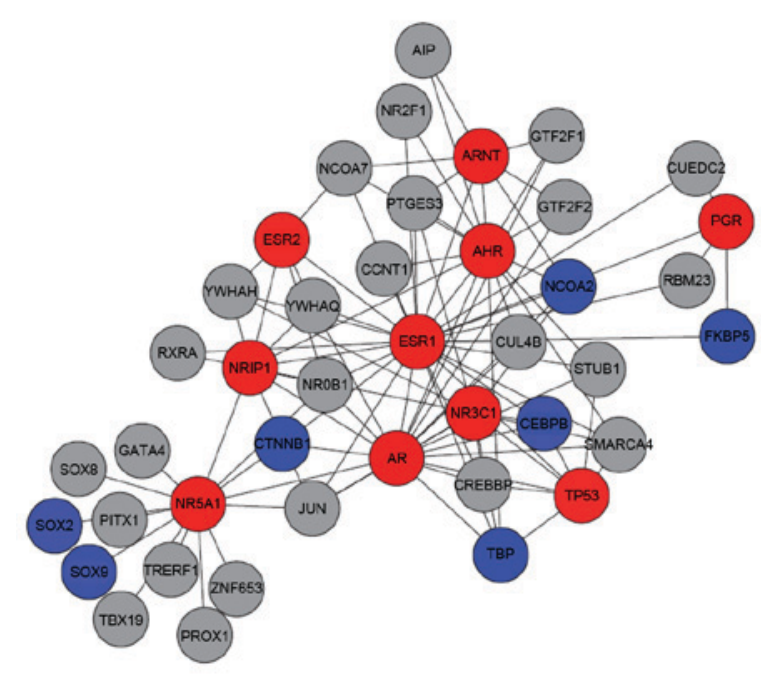

B

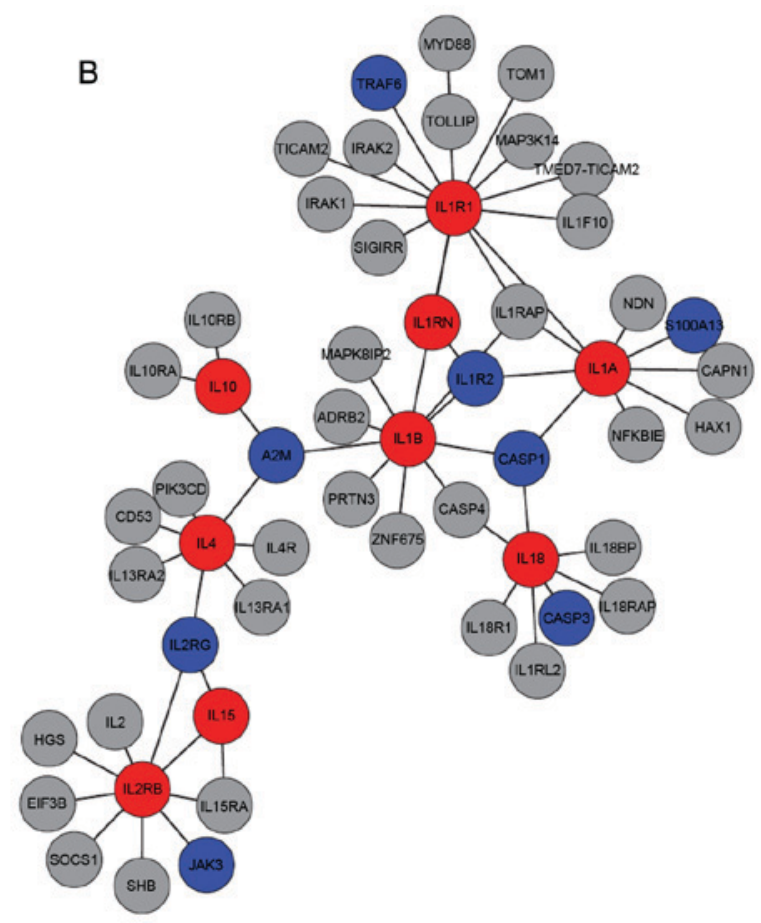

Figure 2. Known and potential endometriosis biomarkers found by protein-protein interaction. The (A) first and (B) second modules are shown. Red circles represent seed genes and blue/grey circles represent the identified endometriosis biomarker genes, based on the seed genes with blue circles being confirmed by literature and grey circles representing currently unconfirmed biomarker genes.

included the osteoclastogenesis pathway, which is predominantly regulated by signaling pathways activated by immune receptors (47).

Matrix metalloproteinases (MMPs) are a family of proteolytic enzymes that share a conserved domain structure. MMPs are capable of degrading various types of extracellular matrix (ECM) and serve an important function in tissue remodeling associated with various physiological and pathological processes (48). The expression of several MMPs is maximal during the menstrual phase in the human endometrium (49). MMPs also have a vital role in the pathogenesis of endometriosis and cancer, particularly in the processes of metastasis and invasion (33,50). MMP1, MMP7, MMP12, MMP13, IGF1, IGFBP1, PAPPA and TIMP2 were identified as the hub genes in module C. ECM-receptor interaction, focal adhesion and proteasomes were also identified in this module, as in previous studies $(32,51,52)$.

The immune response is one of the major factors influencing pathogenesis of endometriosis. Numerous genes in the fourth module are involved in the function of the immune system. Hub genes in this module are members of the HLA gene family, including HLA-A, -B, -C, -DPB1, 
Table III. Details of the 15 potential endometriosis biomarkers in modules A and B demonstrated in literature.

\begin{tabular}{|c|c|c|c|c|}
\hline Gene ID & Gene symbol & Module & PMID & Description \\
\hline 1051 & CEBPB & A & 23097472 & $\begin{array}{l}\text { A novel functional link between } \mathrm{C} / \mathrm{EBP} \beta \text { and STAT3 } \\
\text { that is a critical regulator of endometrial differentiation } \\
\text { in women. }\end{array}$ \\
\hline 1499 & CTNNB1 & A & 23765252 & $\begin{array}{l}\text { CTNNB1 mutations are significantly different in low- } \\
\text { grade ovarian endometrioid carcinomas }(53 \%) \text { compared } \\
\text { with low-grade endometrial endometrioid carcinomas } \\
(28 \% ; \mathrm{P}<0.0057) \text {. }\end{array}$ \\
\hline 2289 & FKBP5 & A & 22279148 & $\begin{array}{l}\text { No significant endometriosis-related change was } \\
\text { observed for FKBP5. }\end{array}$ \\
\hline 6908 & TBP & A & 18252806 & $\begin{array}{l}\text { TBP inhibits the TNF- } \alpha \text {-induced expression of endome } \\
\text { triotic genes in } 12 \mathrm{Z} \text { endometriotic epithelial cells. }\end{array}$ \\
\hline 10499 & NCOA2 & A & 12050280 & $\begin{array}{l}\text { Abnormal increases in endometrial TIF2 and SRC-3 } \\
\text { levels are also associated with infertility in women with } \\
\text { polycystic ovary syndrome. }\end{array}$ \\
\hline 6657 & SOX2 & A & 23670619 & $\begin{array}{l}\text { Samples from endometriosis patients had higher mRNA } \\
\text { expression levels of Oct- } 4, \text { CXCR } 4, \text { SOX } 2 \text { and MET } \\
\text { compared with that of the normal controls. }\end{array}$ \\
\hline 6662 & SOX9 & A & 23847113 & $\begin{array}{l}\text { Cells in ectopic endometriosis lesions also expressed } \\
\text { SSEA-1 and nuclear SOX9. }\end{array}$ \\
\hline 2 & $\mathrm{~A} 2 \mathrm{M}$ & B & 2454848 & $\begin{array}{l}\text { Women with endometriosis had significantly lower } \\
\text { amounts of functional } \alpha-2 \mathrm{M} \text { than did women without } \\
\text { endometriosis. }\end{array}$ \\
\hline 836 & CASP3 & B & 24246915 & $\begin{array}{l}\text { Significantly lower expression of caspase- } 3 \text { protein was } \\
\text { found in ectopic }(3.20 \pm 1.24) \text { and eutopic endometrium } \\
(3.88 \pm 1.93) \text { as compared with the control group } \\
(6.49 \pm 1.85 ; \mathrm{P}<0.01) \text {. }\end{array}$ \\
\hline 7189 & TRAF6 & B & 20130413 & $\begin{array}{l}\text { TRAF2, TRAF6 and TAK1 were constitutively activated } \\
\text { and were unaffected by TSA treatment in endometriotic } \\
\text { cells. }\end{array}$ \\
\hline 834 & CASP1 & B & 17094974 & $\begin{array}{l}\text { Eutopic and ectopic ECs from women with endome } \\
\text { triosis expressed decreased transcript abundance of p53 } \\
\text { and Caspase- } 1 \text { compared to ECs from women without } \\
\text { endometriosis. }\end{array}$ \\
\hline 6284 & S100A13 & B & 15821778 & $\begin{array}{l}\text { Expression of S100A } 13 \text { corresponds to the activation of } \\
\text { the endothelial cells in the process of endometriotic } \\
\text { angiogenesis. }\end{array}$ \\
\hline 7850 & IL1R2 & B & 17482186 & $\begin{array}{l}\text { IL-1RII can neutralize IL-1 } \beta \text { and counteract its effect on } \\
\text { endometrial stromal cells, and may provide a new } \\
\text { clinical strategy for the treatment of endometriosis. }\end{array}$ \\
\hline 3561 & IL2RG & B & 16759924 & $\begin{array}{l}\text { IL2RG was demonstrated to be significantly differen } \\
\text { tially expressed in blood lymphocytes between endome } \\
\text { triosis patients and controls. }\end{array}$ \\
\hline 3718 & JAK3 & B & 17631002 & $\begin{array}{l}\text { JAK3 inhibitors, especially JANEX-1, may prove useful } \\
\text { to prevent or alleviate the symptoms of endometriosis. }\end{array}$ \\
\hline
\end{tabular}

CEBPB, CCAAT/enhancer binding protein $\beta$; CTNNB1, catenin $\beta$ 1; FKBP5, FK506 binding protein 5; TBP, TATA-box binding protein; NCOA2, nuclear receptor coactivator 2; SOX2, SRY-box 2; SOX9, SRY-box 9; A2M, $\alpha$-2-macroglobulin; CASP3, caspase 3; TRAF6, TNF receptor associated factor 6; CASP1, caspase 1; S100A13, S100 calcium binding protein A13; IL1R2, interleukin 1 receptor type 2; IL2RG, interleukin 2 receptor subunit gamma; JAK3, Janus kinase 3.

-DQA1, -DQB1 and -DRB1, which have key roles in the immune response, and it appears that endometriosis shares many similarities with autoimmune diseases $(34,53)$. It has been demonstrated that patients with endometriosis display a significantly higher expression of HLA I and II molecules compared with individuals without endometriosis (54). 
Oxidative stress has been proposed as a potential factor involved in the pathophysiology of endometriosis (55). Accumulation of reactive oxygen species may induce cellular injury, such as DNA damage. The present study demonstrated that the majority of the pathways in module $\mathrm{E}$ were related to replication and repair. APEX1, OGG1, XRCC1, ERCC2 and ERCC5 were the seed genes identified in this module. APEX1 and XRCC1 are key genes involved in the base excision repair pathway, which removes DNA adducts induced predominantly by oxidation and alkylation (56). APEX1 is an essential enzyme and has a central role in the DNA repair system; however, a study by Hsu et al (57) demonstrated that APEX1 Asp148Glu was not associated with endometriosis in patients in Taiwan. Future studies may confirm the association between APEX1 and the risk of endometriosis. XRCC1 has been demonstrated to physically interact with several enzymes known to be involved in the repair of single-strand breaks in DNA (58). A study by Hsieh et al (36) indicated that XRCC1 Arg399Gln polymorphism is correlated with a higher susceptibility to endometriosis.

In conclusion, the pathogenesis of endometriosis is likely multifactorial. The present study constructed a disease network of endometriosis that integrated human protein-protein interactions and known disease-causing genes. The present study has identified a number of biological mechanisms that may be associated with endometriosis. Further studies on the specific function and interactions of the genes in related modules are required to improve the understanding of endometriosis.

\section{Acknowledgements}

The present study was supported by grants from the National Natural Science Foundation of China (grant no. 81360336) and the Joint Special Funds for the Department of Science and Technology of Yunnan Province-Kunming Medical University (grant no. 2015FB017).

\section{References}

1. Podgaec S, Abrao MS, Dias JA Jr, Rizzo LV, de Oliveira RM and Baracat EC: Endometriosis: An inflammatory disease with a Th2 immune response component. Hum Reprod 22: 1373-1379, 2007.

2. Braun DP and Dmowski WP: Endometriosis: Abnormal endometrium and dysfunctional immune response. Curr Opin Obstet Gynecol 10: 365-369, 1998

3. Sha G, Wu D, Zhang L, Chen X, Lei M, Sun H, Lin S and Lang J: Differentially expressed genes in human endometrial endothelia cells derived from eutopic endometrium of patients with endometriosis compared with those from patients without endometriosis Hum Reprod 22: 3159-3169, 2007.

4. Kato N, Sasou S and Motoyama T: Expression of hepatocyte nuclear factor-1beta (HNF-1beta) in clear cell tumors and endometriosis of the ovary. Mod Pathol 19: 83-89, 2006.

5. Kvaskoff M, Mu F, Terry KL, Harris HR, Poole EM, Farland L and Missmer SA: Endometriosis: A high-risk population for major chronic diseases? Hum Reprod Update 21: 500-516, 2015 .

6. Ahn SH, Monsanto SP, Miller C, Singh SS, Thomas R and Tayade C: Pathophysiology and immune dysfunction in endometriosis. Biomed Res Int 2015: 795976, 2015.

7. Hamosh A, Scott AF, Amberger JS, Bocchini CA and McKusick VA: Online mendelian inheritance in man (OMIM), a knowledgebase of human genes and genetic disorders. Nucleic Acids Res 33 (Database issue): D514-D517, 2005.
8. Stenson PD, Mort M, Ball EV, Howells K, Phillips AD, Thomas NS and Cooper DN: The human gene mutation database: 2008 pdate. Genome Med 1: 13, 2009.

9. Becker KG, Barnes KC, Bright TJ and Wang SA: The genetic association database. Nature Genet 36: 431-432, 2004.

10. Wall DP, Pivovarov R, Tong M, Jung JY, Fusaro VA, DeLuca TF and Tonellato PJ: Genotator: A disease-agnostic tool for genetic annotation of disease. BMC Med Genomics 3: 50, 2010.

11. Bauer-Mehren A, Rautschka M, Sanz F and Furlong LI: DisGeNET: A Cytoscape plugin to visualize, integrate, search and analyze gene-disease networks. Bioinformatics 26: 2924-2926, 2010.

12. Lim J, Hao T, Shaw C, Patel AJ, Szabó G, Rual JF, Fisk CJ, Li N, Smolyar A, Hill DE, et al: A protein-protein interaction network for human inherited ataxias and disorders of Purkinje cell degeneration. Cell 125: 801-814, 2006.

13. Pujana MA, Han JD, Starita LM, Stevens KN, Tewari M, Ahn JS, Rennert G, Moreno V, Kirchhoff T, Gold B, et al: Network modeling links breast cancer susceptibility and centrosome dysfunction. Nat Genet 39: 1338-1349, 2007.

14. Jia P, Kao CF, Kuo PH and Zhao Z: A comprehensive network and pathway analysis of candidate genes in major depressive disorder. BMC Syst Biol 5 (Suppl 3): S12, 2011.

15. Vidal M, Cusick ME and Barabási AL: Interactome networks and human disease. Cell 144: 986-998, 2011.

16. Wu G, Feng X and Stein L: A human functional protein interaction network and its application to cancer data analysis. Genome Biol 11: R53, 2010.

17. Schadt EE: Molecular networks as sensors and drivers of common human diseases. Nature 461: 218-223, 2009.

18. Ding Y, Chen M, Liu Z, Ding D, Ye Y, Zhang M, Kelly R, Guo L, Su Z, Harris SC, et al: atBioNet-an integrated network analysis tool for genomics and biomarker discovery. BMC Genomics 13: 325,2012

19. Stark C, Breitkreutz BJ, Chatr-Aryamontri A and Tyers M: The BioGRID Interaction Database: 2011 pdate. Nucleic Acids Res 39 (Database issue): D698-D704, 2010.

20. Xenarios I, Rice DW, Salwinski L, Baron MK, Marcotte EM and Eisenberg D: DIP: The database of interacting proteins. Nucleic Acids Res 28: 289-291, 2000

21. Keshava Prasad TS, Goel R, Kandasamy K, Keerthikumar S, Kumar S, Mathivanan S, Telikicherla D, Raju R, Shafreen B, Venugopal A, et al: Human protein reference database-2009 update. Nucleic Acids Res 37 (Database issue): D767-D772, 2009.

22. Aranda B, Achuthan P, Alam-Faruque Y, Armean I, Bridge A, Derow C, Feuermann M, Ghanbarian AT, Kerrien S, Khadake J, et al: The IntAct molecular interaction database in 2010. Nucleic Acids Res 38 (Database issue): D525-D531, 2010.

23. Licata L, Briganti L, Peluso D, Perfetto L, Iannuccelli M, Galeota E, Sacco F, Palma A, Nardozza AP, Santonico E, et al: MINT, the molecular interaction database: 2012 pdate. Nucleic Acids Res 40(Database issue): D857-D861, 2012.

24. Matthews L, Gopinath G, Gillespie M, Caudy M, Croft D, de Bono B, Garapati P, Hemish J, Hermjakob H, Jassal B, et al: Reactome knowledgebase of human biological pathways and processes. Nucleic Acids Res 37 (Database issue): D619-D622, 2009.

25. Elkon R, Vesterman R, Amit N, Ulitsky I, Zohar I, Weisz M, Mass G, Orlev N, Sternberg G, Blekhman R, et al: SPIKE-a database, visualization and analysis tool of cellular signaling pathways. BMC bioinformatics 9: 110, 2008.

26. Xu X, Yuruk N, Feng Z and Schweiger T: SCAN: A structural clustering algorithm for networks. In: Proceedings of the 13th ACM SIGKDD international conference on Knowledge Discovery and Data Mining. ACM, San Jose, CA, pp824-833, 2007.

27. Kanehisa M and Goto S: KEGG: Kyoto encyclopedia of genes and genomes. Nucleic Acids Res 28: 27-30, 2000.

28. Hwang JH, Oh JJ, Wang T, Jin YC, Lee JS, Choi JR, Lee KS, Joo JK and Lee HG: Identification of biomarkers for endometriosis in eutopic endometrial cells from patients with endometriosis using a proteomics approach. Mol Med Rep 8: 183-188, 2013.

29. Wei WD, Ruan F, Tu FX, Zhou CY and Lin J: Expression of suppressor of cytokine signaling-3 and caspase-3 in endometriosis and their correlation. Zhonghua Bing Li Xue Za Zhi 42: 515-518, 2013 (In Chinese).

30. Hayrabedyan S, Kyurkchiev S and Kehayov I: Endoglin (cd105) and S100A13 as markers of active angiogenesis in endometriosis. Reprod Biol 5: 51-67, 2005 . 
31. Hou Z, Zhou J, Ma X, Fan L, Liao L and Liu J: Role of interleukin-1 receptor type II in the pathogenesis of endometriosis. Fertil Steril 89: 42-51, 2008.

32. Selam B, Kayisli UA, Garcia-Velasco JA and Arici A: Extracellular matrix-dependent regulation of Fas ligand expression in human endometrial stromal cells. Biol Reprod 66: 1-5, 2002.

33. Osteen KG, Yeaman GR and Bruner-Tran KL: Matrix metalloproteinases and endometriosis. Semin Reprod Med 21: 155-164, 2003.

34. de Bakker PI, McVean G, Sabeti PC, Miretti MM, Green T, Marchini J, Ke X, Monsuur AJ, Whittaker P, Delgado M, et al: A high-resolution HLA and SNP haplotype map for disease association studies in the extended human MHC. Nat Genet 38: 1166-1172, 2006

35. Kumar H, Kawai T and Akira S: Toll-like receptors and innate immunity. Biochem Biophys Res Commun 388: 621-625, 2009.

36. Hsieh YY, Chang CC, Chen SY, Chen CP, Lin WH and Tsai FJ: XRCC1 399 Arg-related genotype and allele, but not XRCC1 His107Arg, XRCC1 Trp194Arg, KCNQ2, AT1R and hOGG1 polymorphisms, are associated with higher susceptibility of endometriosis. Gynecol Endocrinol 28: 305-309, 2012.

37. Jiang QY and Wu RJ: Growth mechanisms of endometriotic cells in implanted places: A review. Gynecol Endocrinol 28: 562-567, 2012.

38. Vlahos NF, Economopoulos KP and Fotiou S: Endometriosis, in vitro fertilisation and the risk of gynaecological malignancies, including ovarian and breast cancer. Best Pract Res Clin Obstet Gynaecol 24: 39-50, 2010.

39. Pollacco J, Sacco K, Portelli M, Schembri-Wismayer P and Calleja-Agius J: Molecular links between endometriosis and cancer. Gynecol Endocrinol 28: 577-581, 2012.

40. Jiang X, Hitchcock A, Bryan EJ, Watson RH, Englefield P, Thomas EJ and Campbell IG: Microsatellite analysis of endometriosis reveals loss of heterozygosity at candidate ovarian tumor suppressor gene loci. Cancer Res 56: 3534-3539, 1996.

41. Hsieh YY, Chang CC, Tsai FJ, Hsu CM, Lin CC and Tsai CH: Interleukin-2 receptor beta (IL-2R beta)- $627 * \mathrm{C}$ homozygote but not IL-12R beta 1 codon 378 or IL-18 105 polymorphism is associated with higher susceptibility to endometriosis. Fertil Steril 84: 510-512, 2005.

42. Ayaz L, Celik SK, Cayan F, Aras-Ates N and Tamer L: Functional association of interleukin-18 gene -607 C/A promoter polymorphisms with endometriosis. Fertil Steril 95: 298-300, 2011.

43. Monsanto SP, Edwards AK, Zhou J, Nagarkatti P, Nagarkatti M, Young SL, Lessey BA and Tayade C: Surgical removal of endometriotic lesions alters local and systemic proinflammatory cytokines in endometriosis patients. Fertil Steril 105: 968-977, 2016.
44. Harada T, Iwabe T and Terakawa N: Role of cytokines in endometriosis. Fertil Steril 76: 1-10, 2001.

45. Shuai K and Liu B: Regulation of JAK-STAT signalling in the immune system. Nat Rev Immunol 3: 900-911, 2003.

46. Petrilli V, Dostert C, Muruve DA and Tschopp J: The inflammasome: A danger sensing complex triggering innate immunity. Curr Opin Immunol 19: 615-622, 2007.

47. Harada M, Osuga Y, Hirata T, Hirota Y, Koga K, Yoshino O, Morimoto C, Fujiwara T, Momoeda M, Yano T, et al: Concentration of osteoprotegerin (OPG) in peritoneal fluid is increased in women with endometriosis. Hum Reprod 19: 2188-2191, 2004.

48. Nissinen L and Kähäri VM: Matrix metalloproteinases in inflammation. Biochim Biophys Acta 1840: 2571-2580, 2014.

49. Cominelli A, Gaide Chevronnay HP, Lemoine P, Courtoy PJ, Marbaix E and Henriet P: Matrix metalloproteinase-27 is expressed in CD163+/CD206+ M2 macrophages in the cycling human endometrium and in superficial endometriotic lesions. Mol Hum Reprod 20: 767-775, 2014.

50. Nagase H, Visse R and Murphy G: Structure and function of matrix metalloproteinases and TIMPs. Cardiovasc Res 69: $562-573,2006$

51. Mu L, Zheng W, Wang L, Chen XJ, Zhang X and Yang JH: Alteration of focal adhesion kinase expression in eutopic endometrium of women with endometriosis. Fertil Steril 89: 529-537, 2008.

52. Celik O, Hascalik S, Elter K, Tagluk ME, Gurates B and Aydin NE: Combating endometriosis by blocking proteasome and nuclear factor-kappaB pathways. Hum Reprod 23: 2458-2465, 2008.

53. Nothnick WB: Treating endometriosis as an autoimmune disease. Fertil Steril 76: 223-231, 2001.

54. Kitawaki J, Obayashi H, Kado N, Ishihara H, Koshiba H, Maruya E, Saji H, Ohta M, Hasegawa G, Nakamura N, et al: Association of HLA class I and class II alleles with susceptibility to endometriosis. Hum Immunol 63: D1033-D1038, 2002.

55. Zhang X, Sharma RK, Agarwal A and Falcone T: Effect of pentoxifylline in reducing oxidative stress-induced embryotoxicity. J Assist Reprod Genet 22: 415-417, 2005.

56. Wood RD, Mitchell M, Sgouros J and Lindahl T: Human DNA repair genes. Science 291: 1284-1289, 2001.

57. Hsu CM, Chang WS, Hwang JJ, Wang JY, Hsiao YL, Tsai CW, Liu JC, Ying TH and Bau DT: The role of apurinic/apyrimidinic endonuclease DNA repair gene in endometriosis. Cancer Genomics Proteomics 11: 295-301, 2014.

58. Brem R and Hall J: XRCC1 is required for DNA single-strand break repair in human cells. Nucleic Acids Res 33: 2512-2520, 2005. 